\title{
Early Life Obesity and Diabetes: Origins in Pregnancy
}

\author{
Kilia Yun Liu ${ }^{1}$, Jo May Chow ${ }^{2}$, Christina Sherry ${ }^{2 *}$ \\ ${ }^{1}$ Abbott Nutrition, University of Illinois, Champaign, USA \\ ${ }^{2}$ Abbott Nutrition, Columbus, USA \\ Email: ${ }^{*}$ christina.sherry@abbott.com
}

Received October 10, 2012; revised November 12, 2012; accepted December 15, 2012

\begin{abstract}
The gestational period represent a critical time for influencing birth weight, infant adiposity and growth rate, all of which are important factors in the development of obesity and diabetes in adolescence and adulthood. Prior to pregnancy, the nutritional status and weight of a mother also has significant influence on these factors. During gestation, numerous maternal factors can have a negative influence on programming of the long-term health of the offspring. Rate of maternal weight gain, glucose intolerance, gestational diabetes and pre-pregnancy BMI all have significant influence on infant size and adiposity at birth. Additionally, these factors are related to the development obesity and its co-morbidities in adolescence and adulthood. Given the rates of obesity and associated health care costs, it is very timely to understand possible fetal origins of obesity and diabetes to help shape interventions.
\end{abstract}

Keywords: Gestational Diabetes; Pregnancy; Macrosomia; Gestation Weight Gain; Obesity

\section{Introduction}

The fetal origins of adult diseases are based upon the hypothesis of "programming", the process wherein a stimulus occurring at a critical period of development exerts a lasting effect [1]. Both under and over nutrition have been shown to play a role in impacting cardiovascular function in infants, toddlers, children, adolescent and adults [2], and extensive human epidemiologic data and one pilot study [3] have indicated that prenatal and early postnatal nutrition influence adult susceptibility to diet-related chronic diseases including cardiovascular disease, type 2 diabetes, obesity and cancer [4].

Poor maternal nutrition during gestation causes restriction to fetal growth, leading to increased disease susceptibility in later life. For example, epidemiological data collected from the Dutch famine has demonstrated that under-nutrition during pregnancy can have important effects on health in later life. More specially, maternal under-nutrition causes small body size at birth and these smaller infants are at increased risk of developing coronary heart disease in adult life [5]. This period in history was a unique time indicating that maternal nutrition may affect the intrauterine environment for fetal growth and that malnutrition occurring during the "critical window" for fetal development may program long-term conesquences for adult health. Although the Dutch famine represents an extreme case of maternal under-nutrition, over-nutrition during pregnancy can also cause adverse

*Corresponding author. birth outcomes and lead to various diseases during adult life. Influences at an early age, or what maybe considered the "critical window" of fetal development, can have long-term effects on the offspring and may cause metabolic defects in later life. For instance, some short-term effects of over-nutrition during pregnancy, such as macrosomia [6], can lead to overweight or obesity in later life [7]. Additionally, excess placental transfer of glucose from mother to fetus can cause fetal hyperinsulinemia and lead to impaired glucose tolerance in adulthood [8]. This subsequent increase in one's predisposition to obesity and impaired glucose tolerance (IGT) are the pathophysiological keys for the development of diabetes, hypertension and cardiovascular diseases (CVD) later in life. This review will examine how the maternal variables of weight, insulin and glucose metabolism can have a long-lasting impact on the health of their offspring.

Gestational diabetes mellitus (GDM) is defined by the American Diabetes Association (ADA) as any degree of glucose intolerance with onset or first recognition during pregnancy. The diagnostic criteria for GDM are presented in Figure 1 [9]. This metabolic disorder, whose frequency reflects the underlying pattern of type 2 diabetes in the general adult population [10], affects $7 \%$ of all pregnancies in the US resulting in more than 200,000 cases annually [9]. However, on a world-wide basis, prevalence rates may vary from $0.6 \%$ to $15 \%$ of all pregnancies depending on the population examined and diagnostic criteria used [10]. The prevalence of both pregestational and GMD among women of childbearing age 


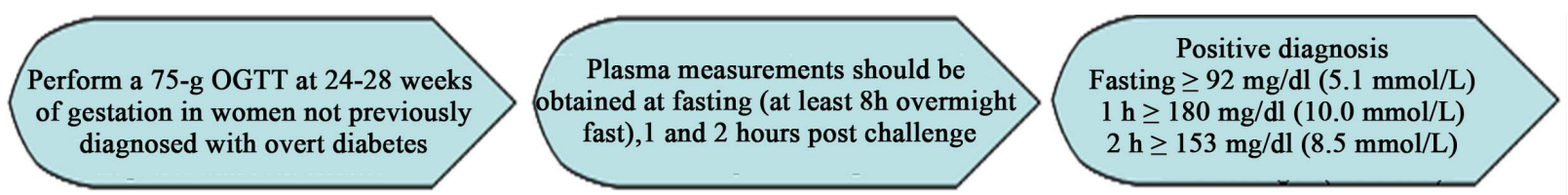

Adapted from: American Diabetes Association. Diagnoisi and classification of diabetes mellitus. Diabetes Care.2012;35 Suppll:S64-71

Figure 1. Diagnosis of gestational diabetes mellitus.

is increasing in the US for a number of reasons, including increased incidence of obesity, a known risk factor for type 2 diabetes [11] as well as increase in average maternal age which is also a known risk factor for GDM [12]. Recent studies indicate that there is a continuum of perinatal risk factors for women with glucose tolerance within the normal range $[13,14]$, and women who develop GDM are also at increased risk of developing type 2 diabetes within 5 to 16 years after the pregnancy with estimates ranging from $17 \%$ to $63 \%$ [15]. Moreover, offspring of mothers who develop either GDM or IGT during pregnancy are more likely to develop glucose intolerance, hyperinsulinemia and macrosomia [8,16-17] and are more likely to develop childhood obesity and type 2 diabetes later in life.

One of the most common fetal outcomes of GDM/IGT is increased fetal growth, including macrosomia and large for gestational age (LGA) infants. Both of these populations are at risk for numerous complications during birth as well as later in life. Birth complications include cesarean delivery, clavicle fracture, nerve damage to the brachial plexus, infant hypoglycemia and respiratory distress [12]. The long-term health implications of fetal macrosomia and LGA infants include increased rate of obesity, metabolic syndrome and related co-morbidities in adolescence and adulthood [18-21]. For children who were LGA at birth, there is an increased hazard ration for metabolic syndromes (2.19 [95\% CI, 1.03 - 3.19] $p=0.04$ ) [22]. Large fetal size in the presence of GDM has also been shown to be a risk factor for the development of childhood obesity and type 2 diabetes later in life $[23,24]$. Although the distinction is slight, fetal macrosomia is different than LGA. Fetal macrosomia refers to excessive intrauterine growth beyond a specific weight, usually $>4000$ g (8 pounds, 13 ounces) or $>4500$ g (9 pounds, 4 ounces), regardless of gestational age. The American College of Obstetrics and Gynecology (ACOG) has found that large cohort studies support the use of $4500 \mathrm{~g}$ as the weight to define fetal macrosomia [12]. The prevalence of fetal macrosomia can vary from $0.5 \%$ to $15 \%$ depending on the definition used [25], and it has been shown that the general North American population has rate of about $10 \%$ [26]. On the other hand, LGA is defined as having a birth weight greater than the 90th percentile for age. There is some debate on whether this should be extended to greater than the 97th percentile as this may more accurately describe those infants who are at the greatest risk for perinatal morbidity and mortality [16,27]. Using a national birth reference for single live births in the US, infants born at 40 weeks of gestation who are at the 90th percentile were $4000 \mathrm{~g}$ and those at the 97th percentile were $4400 \mathrm{~g}$ [28]. Given that most macrosomic infants are also LGA, if born at term, the risk factors for these two conditions are similar at term: maternal pre-pregnancy weight, gestational weight gain (GWG), gestational age > 40 weeks, maternal birth weight and a positive 50-g glucose screen with a negative $3 \mathrm{~h}$ oral glucose tolerance test (OGTT) [12].

There does not appear to be a consensus on the terminology and definitions that should be used to describe impaired glucose tolerance, pre-GDM, hyperglycemia, and/or sub-clinical GDM during pregnancy. Therefore, the terminology used by the authors will be carried over into this review. Nonetheless, the data presented show that not only does frank diabetes during pregnancy, whether preexisting or brought on by pregnancy, lead to long-term programming effects, but other sub-clinical manifestations of dysregulated glucose and insulin metabolism have a long lasting impact as well.

\section{Pre-Pregnancy BMI}

Maternal adiposity in the absence of GDM/IGT is a significant risk factor for macrosomic and LGA infants. Specifically in non-diabetic pregnancies, a 2012 study found that maternal adiposity, as determined by prepregnancy BMI and gestational weight gain, was the strongest, independent predictor of a LGA delivery [29]. Obese mothers also have a 2-fold greater risk for delivering a macrosomic infant than mothers with normal BMI (23\% vs. 11.7\%, $p<0.001$ ) [30]. The adjusted odd ratios of a LGA delivery increased from 1.00, 1.63, to 2.79 in normal, overweight or obese women, respectively [31]. Catalano and colleagues demonstrated that the odds of having LGA deliveries in women with a pre-pregnancy $\mathrm{BMI}>30$ were 3.8 times greater than those women with a BMI < 30 (OR: 3.75, $p=0.0009$ ). Additionally, they found that LGA infants had higher insulin and greater insulin resistance demonstrated by higher insulinto-glucose (I:G) ratio than appropriate-for-gestation age (AGA) infants (insulin level: $20.8 \pm 6.9$ vs. $8.6 \pm 5.3 \mu \mathrm{U} / \mathrm{mL}$; I:G ratio: $0.26 \pm 0.08$ vs. $0.03 \pm 0.005, p<0.05$ ). Large-for- 
gestational infants also had higher free fatty acid levels than AGA babies (213 \pm 83.2 vs. $135 \pm 75.8 \mu \mathrm{U} / \mathrm{mL}, p<$ 0.05) [32].

Higher pre-pregnancy weight is also associated with other negative health outcomes in the fetus such as, spina bifida, heart defects, anorectal atresia, hyposadias, limp reduction defects, diaphragmatic hernia and omphalocele [33]. Obese women were significantly more likely than normal weight women to have children with congenital heart defects [34,35]. A recent meta-analysis has linked maternal obesity with an increase of neural tube defects [36]. Ray et al. found that there is still a higher risk of neural tube defects associated with increased maternal weight, even after universal folic acid flour fortification even though this population consumes greater quantities of refined wheat flour [37]. Pre-pregnancy BMI also influences later obesity in the offspring. Catalano's group conducted a study examining the perinatal risk factors related to childhood obesity and found the strongest perinatal factor to predict that a child would be in the upper tertile for weight and percent body fat was maternal pre-pregnancy BMI (BMI > 30: odds ratio 3.75 [95\% CI, $1.39-10.10] p=0.009$ and odds ratio 5.45 [95\% CI, $1.62-18.41] p=0.006$, respectively).

\section{Gestational Diabetes Mellitus (GDM)}

Pre-pregnancy overweight or obesity is also one of the most well documented risk factors for GDM. A recent meta-analysis found that increasing pre-pregnancy BMI was associated with an increased risk of developing GDM. The unadjusted odd ratios of developing GDM were 2.14 (95\% CI 1.82 - 2.53) among overweight women, 3.56 (95\% CI 3.05 - 4.21) among obese women and 8.56 (95\% CI 5.07 - 16.04) among severely obese women (>BMI 29) [38]. Leung et al. also assessed the effect of BMI on pregnancy outcomes in the Chinese population and found that the risk of GDM increased in the highest BMI group compared to the normal weight group (odd ratios of 4.18 vs. $1.75, p<0.05$ ) [39]. The risks for IGT during pregnancy were higher for those who were over- weight or obese as compared to normal or underweight individuals before becoming pregnant (4.4\% or $3.2 \%$ vs. $1.5 \%$ or $1.5 \%, p<0.05$ ) [40].

When a mother has uncontrolled diabetes during pregnancy, maternal glucose is freely transferred to the fetus, but maternal insulin does not cross the placenta. The risk of major malformations and disease later in life for the fetus is increased due to uncontrolled hyperglycemia in the mother during pregnancy. The developing fetal pancreas responds to a glucose load by producing insulin, which acts as a fetal growth hormone in addition to its hypoglycemic effects. This in-utero environment results in excess growth leading to fetal macrosomia and likely a LGA infant at birth [22]. Catalano et al. investi- gated the association of adverse pregnancy outcomes related to GDM and obesity and demonstrated that the odds of having a LGA infant (birth weight > 90th percentile) were greater for women with GDM (2.19) and obese women (1.73), and among the highest for obese women with GDM (3.62) [41]. When compared with women that are normal/underweight with a normal glucose tolerance, the relative odds of having a LGA infant is 2.58-fold greater for women with GDM and 2.07-fold greater for obese pregnancies [41]. Additionally, excess weight gain in a GDM pregnancy increases the risk of macrosomia. Hillier et al. found that $30 \%$ of women with GDM gaining more than 40 pounds had a macrosomic infant as compared with $13 \%$ of women with GDM gaining less than 40 pounds [42]. Another study demonstrates that within GDM pregnancies there is a difference in fetal macrosomia and LGA infants. Although there was not a significant difference in the proportion of macrosomic infants (>4000 g) in control vs. GDM pregnancies, there was a significant increase in LGA infants in the GDM group ( $27 \%$ vs. $14 \%, p=0.004)$ [43]. There are a few possible explanations for this finding. Based on the previous AGOC recommendations, macrosomia is $>4500 \mathrm{~g}$ and this study used a cut-off of $4000 \mathrm{~g}$. Additionally, in this study as in many other studies, the length of gestation in the GDM pregnancies was significantly shorter by 4 days as compared to control pregnancies; therefore it is more likely that macrosomic infants that are born early are more likely to be larger for their gestational age than others.

Infant growth rate and adiposity during the first year of life are strong predictors of later health outcomes. Numerous epidemiological studies now support the hypothesis that rapid weight gain (upward centile crossing for weight) during infancy impacts programming for the development of later health concerns, such as obesity and cardiovascular disease; this early growth hypothesis is further reviewed elsewhere [44]. The "critical window" for these growth effects is not known, but slower weight gain in the first few weeks, is associated with a lower risk of later obesity [45,46], insulin resistance [47], endothelial dysfunction [48] and adult obesity [49]. Maternal programming can also have an influence on the rate of post-natal weight gain. Several studies comparing growth rates of offspring of diabetic mothers compared to non-diabetic mothers demonstrate that there are significant differences in the growth patterns related to GDM, in particular the weight gain of offspring of diabetic mothers greatly exceeds that of offspring of non-diabetic mothers [50,51]. Infant adiposity during the first year of life has also been related to undesirable health outcomes in adult life [52-54]. Maternal insulin sensitivity, independent of glucose tolerance [53] was found to be a significant predictor of infant weight gain 
and adiposity during the first year of life. Finally, it has also been demonstrated that children of mothers with GDM had higher fasting insulin as well as higher insulin resistance compared to those of mothers with normal glucose tolerance at follow-up at $8.8 \pm 1.8$ years of age (insulin: $78 \pm 43 \mathrm{pmol} / \mathrm{L}$ vs. $50 \pm 24 \mathrm{pmol} / \mathrm{L}, p=0.02$; HOMA-IR: $2.86 \pm 1.64$ vs. $1.81 \pm 0.86, p=0.02$ ) [32].

Other metabolic changes in pregnancy have also been shown to be related to neonatal fat mass. Schaefer-Graf and colleagues examined the contribution of maternal lipids to the intrauterine metabolic environment and infant fatness of women with GDM. In this study they found that maternal free fatty acid (FFA) levels in late pregnancy are positively correlated with neonatal fat mass ( $\mathrm{r}=0.27, p=0.01$ ) and fetal FFA levels measured in cord blood serum $(\mathrm{r}=0.28, p=0.004)$ [55]. In animal studies, high levels of triglycerides in maternal circulation of diabetic rats may accelerate fatty acid transport across placenta and deposition in to fetal tissues [24]. This increase in FFA concentration is related to the inability of insulin to suppress lipolysis in late gestation of diabetic women. Insulin's ability to suppress FFA levels declined in obese women with GDM compared to the normal subjects during late gestation $(68.5 \% \pm 15 \%$ vs. $79 \% \pm$ $5 \%, p=0.025$ ) [6]. This may be because obese women with GDM had significantly lower levels of key proteins involved in the mechanism by which insulin suppresses lipolysis (43\% lower insulin receptor substrate-1 (IRS-1) protein and $48 \%$ lower peroxisome proliferator-activated receptor- $\gamma$ (PPAR- $\gamma$ ) mRNA and protein) as compared to obese women without GDM resulting in reduced insulin-stimulated suppression of lipolysis, as well as accelerated fat catabolism to meet fetal nutrient demands [56].

Finally, offspring of the obese women with GDM are also reported to weight more at birth due to increased fat mass not lean body mass [6]. A study of 195 women with GDM demonstrated that there was a significantly greater increase in neonatal fat mass in GDM pregnancies. There was an increase in skin fold measures as well as estimates of body composition (as measured by total body electrical conductivity) showing that infants of women with GDM haves less free-fat mass $(2832 \pm 286 \mathrm{~g}$ vs. $2919 \pm 287 \mathrm{~g}, p=0.008)$, increased fat mass (371 \pm 163 g vs. $329 \pm 150$ g, $p=0.02)$ and percent body fat $(11.4 \%$ $\pm 4.6 \%$ vs. $9.9 \% \pm 4 \%, p=0.002$ ) as compared to controls [43]. A significant finding of this study is that infants born to women with GDM, even when they were average weight for gestational age, had increased body fat composition compared with infants of women with normal glucose tolerance.

\section{Dysregulated Insulin and Glucose Metabolism}

Fetal hyperinsulinemia in-utero has been implicated in later metabolic dysregulations through malprogramming of the neuroendocrine system. High levels of glucose concentration in-utero can have a permanent influence on the function of pancreatic $\beta$-cells; in particular a persistent $\beta$-cell hyperactivity can lead to permanent impairment of insulin secretion in the offspring [57]. This fetal hyperinsulinemia can increase insulin concentrations within the immature hypothalamus leading to life-long abnormal development of the central nervous nuclei that regulate carbohydrate metabolism and body weight. Plagemann hypothesized that elevated concentrations of insulin itself, when occurring in during "critical” perinatal periods of brain development, may cause malprogramming of neuroendocrine systems that regulate body weight and metabolism. Therefore, excessive fetal insulin production has been identified as a teratogen that can affect the hypothalamic response to satiety in early development and may maintain throughout life [58].

The hypothalamic centers in the brain act as the central neural modulators for insulin production. The ventromedial hypothalamic nuclei (VMH) and lateral hypothalamic area (LHA) are key brain regions that can impact insulin secretion and regulate satiety [59]. It has been demonstrated that the disruption of the VMH will cause hyperphagia and increased body weight leading to overt obesity [60]. Several animal studies have been conducted to investigate the teratogenic effects of excessive insulin production on fetal brain development. Newborn male Wistar-rats received insulin implants into the hypothalamus on the 2nd or 8th day of life and compared with the control animals, the 2nd day insulin implanted rats had increased relative body weight per body length (18.6 $\pm 0.96 \mathrm{~g} / \mathrm{cm}$ vs. $17.8 \pm 0.53 \mathrm{~g} / \mathrm{cm}, p<0.05)$ and decreased glucose tolerance in juvenile life and in adulthood $(11.0 \pm 0.6 \mathrm{mmol} / \mathrm{L}$ vs. $6.5 \pm 0.9 \mathrm{mmol} / \mathrm{L} 90$-minutes post glucose load, $p<0.02$ ). These results were more pronounced in the 8th day insulin implanted rats (weight gain: $20.6 \pm 0.99 \mathrm{~g} / \mathrm{cm}$ vs. $17.5 \pm 1.31 \mathrm{~g} / \mathrm{cm}, p<0.0001$; glucose tolerance: $9.5 \pm 0.5 \mathrm{mmol} / \mathrm{L}$ vs. $7.0 \pm 0.3$ $\mathrm{mmol} / \mathrm{L} 90$-minutes post glucose load, $p<0.0001)$. Additionally, a significant increased in basal insulin levels were observed in 8th day insulin implanted rats compared to control rats $(16.0 \pm 7.5 \mu \mathrm{IU} / \mathrm{mL}$ vs. $31.0 \pm 1.5 \mu \mathrm{IU} / \mathrm{mL}$, $p=0.02)$. Both groups also had increased diabetes susceptibility to a single low-dose of streptozotocin with these effects being more pronounced in the 8th day group (2nd day group: $10.0 \pm 1.5 \mathrm{mmol} / \mathrm{L}$ vs. $5.5 \pm 0.35$ $\mathrm{mmol} / \mathrm{L}, p<0.05$; 8th day group: $14.0 \pm 1.5 \mathrm{mmol} / \mathrm{L}$ vs $7.5 \pm 0.85 \mathrm{mmol} / \mathrm{L}, p<0.01)$. Therefore, the 8th postnatal day appears to be the critical window for brain development in rats, as rodents are born premature compared to human. Based on these findings, the critical window for brain development in human would be about 28 weeks of gestation (Figure 2), and screening for GDM usually occurs 
Gestational weeks for human

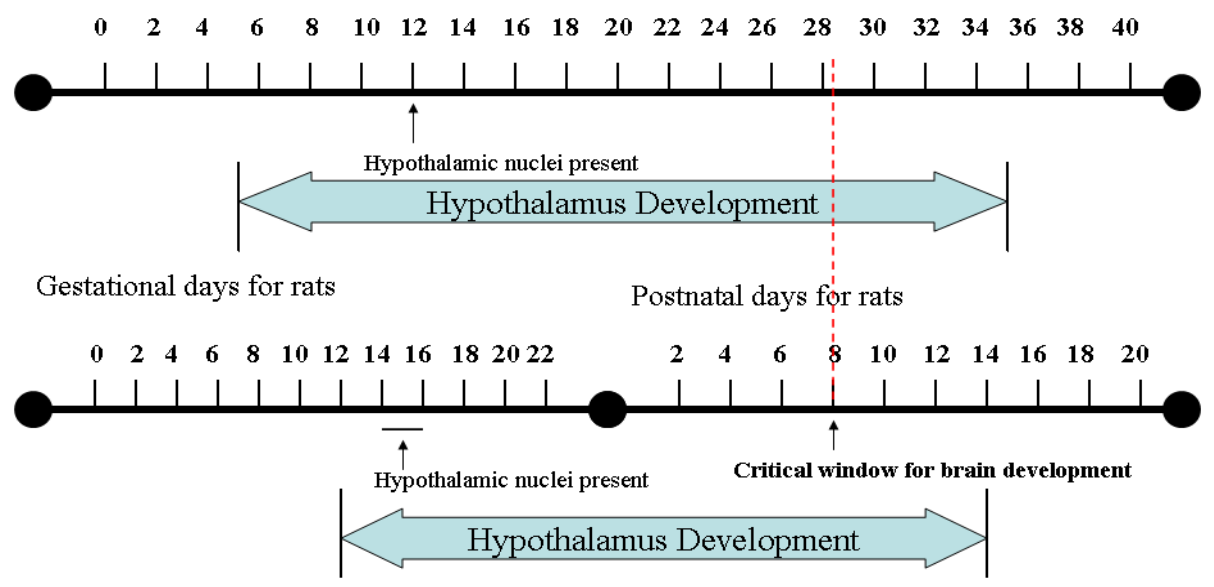

Adapted from: Howdeshell, KL. A Model of the Development of the Brain as a Construct of the Thyroid System. Endocrine Disruptors. 2002;110:337-48.

Figure 2. Timeline of human and rats brain development gestational weeks for human.

between 24 - 28 weeks [61]. This overlap suggests that the development of GDM along with any negative impacts may coincide with key brain development of glucose regulation and excess insulin in hypothalamus during the "critical window" of brain development and this may increase the susceptibility of obesity and diabetes in later life. Further confirmation of this work demonstrated that both central and peripheral insulin during the critical period of brain development significantly impacts metabolic outcomes in juvenile and adult life. Both the insulin-implanted rats (intrahypothalamic on 8th postnatal day) and the insulin-injected rats (subcutaneous insulin injecttions 8th to 11th postnatal day) had significantly higher basal plasma insulin level compared to their respective controls (Insulin implanted vs. control: $47.8 \pm 8.11 \mu \mathrm{IU} / \mathrm{mL}$ vs. $31.6 \pm 2.11 \mu \mathrm{IU} / \mathrm{mL}$; Insulin-injected vs. control: 22.0 $\pm 2.97 \mu \mathrm{IU} / \mathrm{mL}$ vs. $13.2 \pm 0.84 \mu \mathrm{IU} / \mathrm{mL}, p<0.02)$. Taken together, these studies demonstrate that hyperinsulinemia during brain development may be a risk factor for diabetes and/or obesity.

As previously mentioned is a positive $50-\mathrm{g}$ glucose screen with a negative 3-h OGTT is risk factor for macrosomia/LGA infants [12] suggesting that pre-diabetes and sub-clinical dysregulation of insulin and glucose metabolism during pregnancy is also a contributing factor to fetal macrosomia and LGA infants. Interestingly, women with pre-GDM are at higher risk for offspring with major organ structural anomalies as it is related to the degree of glucose control during organogenesis (6 - 8 weeks gestation). However, women with normal prepregnancy glucose who development GDM in late gestation do not show an increased risk of fetal congenital anomalies [62]. A study conducted in southern Sweden demonstrated that women with impaired glucose toler- ance defined by the World Health Organization (WHO) (OGTT of 7.8 to $8.9 \mathrm{mmol} / \mathrm{L}$ ) had over a 2-fold increase in the percent of infant macrosomic infants $(4.5 \%$ vs. $9.9 \%, p<0.001)$ and significant increase in gestation $>$ 37 weeks $(5.7 \%$ vs. $8.5 \%, p<0.001)$ and it was concluded that women with 2-h OGTT of $7.8-8.9 \mathrm{mmol} / \mathrm{L}$ are at increased risk for non-optimal delivery outcomes [13]. In the retrospective Cambridge Wellbeing Study of 3158 full-term, singleton pregnancies with normal glucose tolerance, it was demonstrated that within the non-diabetic range $(2.1-7.8 \mathrm{mmol} / \mathrm{L})$, each $1 \mathrm{mmol} / \mathrm{L}$ increase in the 1-h OGTT value was associated with a 46 $\pm 8 \mathrm{~g}$ increase in offspring birth weight and a continuous trend was apparent across the range of normal glucose levels [14]. In the prospective Cambridge Baby Growth Study of 668 non-diabetic pregnancies with normal fasting glucose and glucose tolerance it was demonstrated that maternal fasting glucose was more strongly related to offspring skin folds and birth weight than birth length. Additionally, the risk of fetal macrosomia was independently related to maternal fasting glucose (odds ratio of fetal macrosomia was $2.61 \mathrm{per}+1 \mathrm{mmol} / \mathrm{L}$ ) [14]. In this study there was a relationship of maternal glycemia and infant adiposity at birth, and this relationship continued from 3 months onward. Maternal pre-pregnancy BMI did show a sustained relationship with infant adiposity at 12 and 24 months [14]. Overall it was observed that increased maternal glucose levels, even within normal non-diabetic ranges, were consistently related to fetal macrosomia and LGA deliveries. Although not fully explored in this review, these studies also demonstrated increased risk of complications during delivery.

The Hyperglycemia and Adverse pregnancy Outcome 
(HAPO) study was conducted to determine the risk of adverse outcomes associated with increased hyperglycemia during pregnancy that were less severe than frank GDM. Metzger et al. investigated the relationship between neonatal adiposity, maternal glucose and fetal insulin and found that increasing glucose concentration during pregnancy was associated with fetal overgrowth, particularly with adiposity [63]. In this study eligible pregnant women underwent a standard 75-g oral glucose tolerance test between 24 and 32 weeks of gestation (as close to 28 weeks as possible) and plasma glucose levels were measured during fasting, $1 \mathrm{~h}$ and $2 \mathrm{~h}$. For every one increase in plasma glucose at baseline, fasting, $1 \mathrm{~h}$ and 2 h $(0.4 \mathrm{mmol} / \mathrm{L}, 1.7 \mathrm{mmol} / \mathrm{L}$, and $1.3 \mathrm{mmol} / \mathrm{L}$, respecttively) resulted in approximately a $10 \%$ increase in neonatal adiposity, as measured by skin folds and percent body fat (>90th percentile). Thus this study presented a strong and continuous association between maternal glycemia and neonatal fat content [63] and confirms the link between increased fetal insulin production induced by excess placental transport of glucose from mother to fetus and fetal overgrowth and adipose deposition.

Several studies have looked at longer term follow-up of children to determine how the in-utero environment has impacted their health status as toddlers and young children. Pettitt et al. used the HAPO cohort to examine the relationship of maternal glycemia with neonatal anthropometry at a 2-year follow-up and found an association between increased maternal glucose after 1-h glucose challenge and overweight status at 2 years of age. Additionally, there is a trend in the association between increased maternal glucose after 2-h glucose challenge and overweight status at age of 2 years. Neonatal fatness (either birth weight or sum of skin folds) was also strongly associated with overweight and obesity at age 2 years [7]. Finally, increased maternal hyperglycemia during pregnancy is associated with increased future risk for obesity in their children at age 5 - 7 years, and greater than or equal to 1 abnormal value on an OGTT, in particular fasting hyperglycemia, is an important predictor of future childhood obesity [64].

\section{Gestational Weight Gain (GWG)}

Excess gestational weight (GWG) gain during pregnancy also impacts fetal size and fat mass at birth, which may lead to obesity or diabetes later in life [6,22,65]. In a study of Vietnamese women, increasing GWG from 15 $\mathrm{kg}$ to $20 \mathrm{~kg}$ to $25 \mathrm{~kg}$ resulted in a significant increase in the risk of macrosomic deliveries from $10 \%$ to $20 \%$ to $35 \%$, respectively [30]. Weight gain of more than 40 pounds (which is greater than recommended for anyone expect those with low BMI) has been shown to almost doubled the rate of macrosomic births for each increase in quintile of the maternal glucose challenge test [42]. Another study also echoes this result demonstrating a $35 \%$ increase in LGA infants for women gaining more than 45 pounds during pregnancy [66]. Several studies have investigated the relationship between excess GWG in overweight/obese pregnancies and infant birth weight and have demonstrated that an excess 15 to $20 \mathrm{~kg}$ weight gain resulted in a 2 -fold increased risk of having a LGA infant [30,31].

The Institute of Medicine (IOM) released a report in 2009 which included revised weight gain recommendations for all pregnant women (Table 1). According to these guidelines, women should be within a normal BMI range when they conceive and should gain within the ranges recommended in order to improve maternal and child health outcomes [67]. The new guidelines are formulated as a range of weight gain for each category of pre-pregnancy BMI to better accommodate for differrences such as age, race/ethnicity and other factors that may affect pregnancy outcomes. In addition to accommodating for these factors, the range of gestational weight gain recommended by IOM could also balance the risks of small-for-gestational-age births (SGA), LGA, spontaneous preterm births and medically indicated preterm births [68]. Gaining excessive weight during pregnancy beyond these guidelines, excessive GWG can have negative consequences for both the mother and infant. General adherence to the earlier 1990 IOM pregnancy weight gain guidelines (Table 2) [69] was poor, and

Table 1. IOM 2009 new recommendations: total and rate of weight gain during pregnancy.

\begin{tabular}{cccc}
\hline & Total weight gain & Rates of weight gain ${ }^{*}$ 2nd and 3rd trimester \\
\hline Pre-pregnancy BMI & Range in kg & Range in lbs & Mean (range) in kg/week $\quad$ Mean (range) in lbs/week \\
Underweight $\left(<18.5 \mathrm{~kg} / \mathrm{m}^{2}\right)$ & $12.5-18$ & $28-40$ & $0.51(0.44-0.58)$ \\
Normal weight $\left(18.5-24.9 \mathrm{~kg} / \mathrm{m}^{2}\right)$ & $11.5-16$ & $25-35$ & $0.42(0.35-0.5)$ \\
Overweight $\left(25-29.9 \mathrm{~kg} / \mathrm{m}^{2}\right)$ & $7-11.5$ & $15-25$ & $0.28(0.23-0.33)$ \\
Obese $\left(\geq 30 \mathrm{~kg} / \mathrm{m}^{2}\right)$ & $5-9$ & $11-20$ & $0.22(0.17-0.27)$ \\
\hline
\end{tabular}

*Calculations assume 0.5 - 2 kg (1.1 - 4.4 lbs (weight gain)). Adapted from: [67]. 
Table 2. 1990 IOM recommendations: total and rate of weight gain during pregnancy.

\begin{tabular}{ccc}
\hline Pre-pregnancy BMI & $\begin{array}{c}\text { Total weight gain } \\
\text { (lbs) }\end{array}$ & $\begin{array}{c}\text { Rate of weight gain } \\
\text { 2nd and 3rd trimester } \\
\text { (lb/week) }\end{array}$ \\
\hline $\begin{array}{c}\text { Underweight } \\
\left(<19.8 \mathrm{~kg} / \mathrm{m}^{2}\right)\end{array}$ & $28-40$ & $\sim 1(0.5 \mathrm{~kg} /$ week $)$ \\
$\begin{array}{c}\text { Normal weight } \\
\left(19.8-26 \mathrm{~kg} / \mathrm{m}^{2}\right)\end{array}$ & $25-35$ & $1(0.4 \mathrm{~kg} /$ week $)$ \\
$\begin{array}{c}\text { Overweight } \\
\left(26-29 \mathrm{~kg} / \mathrm{m}^{2}\right)\end{array}$ & $15-25$ & $0.66(0.3 \mathrm{~kg} /$ week $)$ \\
$\begin{array}{c}\text { Obese } \\
\left(\geq 29 \mathrm{~kg} / \mathrm{m}^{2}\right)\end{array}$ & $\geq 15$ & Not specified \\
\hline
\end{tabular}

Adapted from: [69].

studies show that between one-half [70] and two-thirds [71] of women were not gaining according these guidelines, which where are more liberal for overweight and obese women as compared to the most recent guidelines. The previous recommendations for women for obese women (BMI > 30), was to gain at least $15 \mathrm{lbs}$, but the newer recommendations slightly lowered the recommended range of weight gain and placed an upper bound limit for obese women (Table 1). There has been a dramatic increase in the prevalence of overweight and obese women of childbearing age over the past 20 years. Since the previous 1990 IOM guidelines were issued, the proportion of overweight/or obese women (BMI $\geq 25$ ) of reproductive age has increased from $37 \%$ to $59.5 \%$ in 2007-2008 [72] resulting in a situation where more women are entering pregnancy overweight or/obese and likely only about half are gaining weight as recommended, both rate of weight gain and absolute amount.

Women whose BMI gained 3 or more units during pregnancy have higher risk for pre-eclampsia, gestational hypertension, gestational diabetes, caesarean delivery, stillbirth and LGA infants [73]. Herring and colleagues also found that women who gained the largest amount of weight had an increased risk of impaired glucose tolerance during pregnancy. This study demonstrated that increased GWG in the range of $12.9-29.1 \mathrm{~kg}$, which is significantly over the IOM recommendation depending on the women's pre-pregnancy BMI, had 2.5-fold increased risk of developing IGT in pregnancy compared to women who gained less weight $(p<0.05)$. Furthermore, they found that the risk of IGT was more pronounced when the excess GWG occurred in early and mid-pregnancy [74]. Not surprisingly, excess GWG may have a more deleterious impact on obese women. Obese women exceeding the rate and/or total amount of GWG had a 3 - 4 fold increase in the risk of abnormal glucose tolerance as compared to those gaining within recommendations [75]. Interestingly, the impact of GWG on those who develop GDM is two-sided. In a retrospective study of women diagnosed with GDM, those who gained greater than the 1990 IOM recommendations had increased odds of LGA infants, preterm delivery and primary cesarean section and those gaining less than the guidelines had increased odds of small-for-gestational age infants [76].

Gestational weight gain can also impact later measures of obesity and was shown to have a linear relationship with adolescent adiposity. Excess GWG beyond the 1990 IOM guidelines (those current at the time of the study) resulted in children with higher BMI z scores (0.14 units [95\% CI, $0.09-0.18]$ ) and risk of obesity (odds ration 1.42 [95\% CI, 1.19 - 1.70]) [66]. Gestational weight gain also has long-term implications. Offspring of women in the highest quartile of GWG (>7 kg in the first 20 weeks) had an increased risk of overweight/obesity and abdominal obesity in adolescence at 16 years of age (OR 1.46 [95\% CI, 1.16 - 1.81]; OR 1.37 [95\% CI, 1.10 - 1.72], respectively) [77]. Finally, a review article by Dietz focusing on the potential factors for developing childhood obesity suggests that reduced fetal fat deposition by limiting the amount of maternal weight gain in late pregnancy may help prevent subsequent obesity, as the last trimester of pregnancy represents a period of fetal adipocyte replication and rapid increase in body fat [78]. Overall, these studies demonstrate that not only does inutero programming have an impact on the immediate health of the infant (birth size, adiposity and growth rate), but also on later measures of adiposity.

\section{Intervention and Conclusion}

\subsection{Nutritional Strategies for Improving Maternal Programming}

Based on the evidence presented it can be concluded that there is a continuum of overweight/obesity which contributes to dysregulated insulin and glucose metabolism, culminating in GDM. This environment during pregnancy contributes to in-utero programming of sub-optimal health later in life. Given the interdependencies of all these factors it would be beneficial for all women of childbearing age, especially those planning a pregnancy, to adhere to recommendations to help improve maternal health prior to as well as during pregnancy to most effecttively benefit the health of the next generation. As recommended by the IOM in their most recent 2009 report, achieving a normal weight prior to conception is the most optimal situation for both maternal and infant health outcomes [67]. The methods by which one should try and obtain a normal weight are beyond the scope of this review; however, especially for those planning a pregnancy providing information and education on the risks and long-term impact of overweight/obesity and a poor nutriation before and during pregnancy will hopefully provide additional motivation for changing one's lifestyle. 
As represented by the approximately 2/3 of women of childbearing age who are overweight and obese it is clear that IOM recommendations are not being met. There has been extensive research to examine interventions during pregnancy aimed to improve maternal weight and a whole host of obstetric outcomes. Although there is a wide range of variables and outcomes in these studies, a few recent reviews have summarized the impact of interventions during pregnancy. Despite the different results, one promising finding was the overall safety of dietary and physical activity interventions during pregnancy [79-82]. Given the complex nature of problem, numerous interventions used and outcomes measured, it is not wholly surprising that a single consensus was not reached on the best method for preventing excess gestational weight and to improve maternal and fetal outcomes. These reviews [80-82] examined a combined 86 studies and found that dietary interventions appear to be the most effective at reducing excess GWG with a reduction from $1.92 \mathrm{~kg}$ [81] to $5.22 \mathrm{~kg}$ [82]. A reduction in GWG also leads to a significant reduction in GDM, (61\% reduced risk, $0.39,0.23$ to $0.69 ; p=0.001, I^{2}=21 \%$ ) [82], a trend towards a reduced risk OR 0.80 [95\% CI, 0.58 1.10]) [80], or no significant impact [81]. Another review specifically examining prevention of GDM with dietary interventions found that higher dietary fat, in particular saturated fat and lower carbohydrate intake appeared to be associated with a higher risk for developing GDM. In this review, dietary intervention was also found to significantly decrease the GWG in women with GDM [79]. The dietary recommendations during pregnancy are not that different than those proposed by these reviews including a balanced, low glycemic diet with whole grains, fruits, non-starchy vegetables, lean protein and low-fat dairy with a macronutrient distribution of 30\% fat, $15 \%$ $20 \%$ protein and 50\% - 55\% carbohydrate and individualized calorie needs.

\subsection{Conclusion and Future Direction}

Our objective was to review the scientific literature on the association of in-utero factors that can have an influence on later health outcomes with a focus on later obesity and diabetes. Results from this literature review highlight the numerous parameters of the pre-pregnancy and pregnancy milieu that can impact the long-term health of the offspring. Infant size and adiposity at birth, as well as excessive infant growth rates have been associated with long-term health complications. Large-forgestational age infants, especially those exposed to glucose intolerance and/or GDM, are at a greater risk for developing metabolic syndrome [19]. Higher birth weight is also associated with increased infant fat mass [83], increased risk of developing type 2 diabetes [84] and hypertension in children [85]. A fast rate of weight gain the first few weeks of life has been associated with long-term adverse effects in CVD [86-89] and a greater risk of adult obesity $[86,88,90]$. This review has also demonstrated that maternal characteristics before and during pregnancy also play a significant role in determining the long-term health outcomes in the offspring. Most notably are the increased risks for increased intrauterine growth, infant fat mass and later development of diabetes in the offspring of diabetic mothers. Moreover, we can now appreciate the long-term impact sub-clinical GDM and glucose intolerance during pregnancy plays in the future health of the offspring. In the greater context of the obesity epidemic, women of child bearing age are not meeting the guidelines for weight management prior to and during pregnancy. Recent reviews have demonstrated promising results that dietary interventions can be safe and effective during pregnancy to help reduce excess GWG. An area of research that currently has minimal data would be to examine the best dietary intervenetions which have the greatest impact on neonatal health. It would be of great interest to the field to develop and evaluate dietary interventions during pregnancy that are not only effective at mitigating excess GWG but also result in improvements in neonatal health.

\section{REFERENCES}

[1] A. Lucas, "Programming by Early Nutrition: An Experimental Approach,” Journal of Nutrition, Vol. 128, No. 2, 1998, pp. 401S-406S.

[2] L. Poston, "Influences of Maternal Nutritional Status on Vascular Function in the Offspring," Current Drug Targets, Vol. 8, No. 8, 2007, pp. 914-922.

[3] A. Singhal, "The OPTIGROW Infant Feeding Study," Unpublished.

[4] J. A. Armitage, I. Y. Khan, P. D. Taylor, P. W. Nathanielsz and L. Poston, "Developmental Programming of the Metabolic Syndrome by Maternal Nutritional Imbalance: How Strong Is the Evidence from Experimental Models in Mammals?” The Journal of Physiology, Vol. 561, Pt. 2, 2004, pp. 355-377.

[5] T. J. Roseboom, J. H. van der Meulen, A. C. Ravelli, C. Osmond, D. J. Barker and O. P. Bleker, "Effects of Prenatal Exposure to the Dutch Famine on Adult Disease in Later Life: An Overview,” Twin Research, Vol. 4, No. 5, 2001, pp. 293-298.

[6] P. Catalano, "Obesity, Inuslin Resistance and Pregnancy Outcome," The Society for Reproduction and Fertility, Vol. 140, No. 3, 2010, pp. 365-371.

[7] D. J. Pettitt, S. McKenna, C. McLaughlin, C. C. Patterson, D. R. Hadden and D. R. McCance, "Maternal Glucose at 28 Weeks of Gestation Is not Associated with Obesity in 2-Year-Old Offspring," Diabetes Care, Vol. 33, No. 6, 2010, pp. 1219-1223.

[8] L. S. Fetita, E. Sobngwi, P. Serradas, F. Calvo and J. F. Gautier, "Consequences of Fetal Exposure to Maternal 
Diabetes in Offspring," Journal of Clinical Endocrinology and Metabolism, Vol. 91, No. 10, 2006, pp. 3718-3724.

[9] American Diabetes Association, "Diagnosis and Classification of Diabetes Mellitus,” Diabetes Care, Vol. 35, Suppl. 1, 2012, pp. S64-S69.

[10] H. King, "Epidemiology of Glucose Intolerance and Gestational Diabetes in Women of Childbearing Age," Diabetes Care, Vol. 21, Suppl. 2, 1998, pp. B9-B13.

[11] L. K. Khan and B. A. Bowman, "Obesity: A Major Global Public Health Problem,” Annual Review of Nutrition, Vol. 19, 1999, pp. xiii-xvii.

[12] J. Chatfield, “ACOG Issues Guidelines on Fetal Macrosomia. American College of Obstetricians and Gynecologists," American Family Physician, Vol. 64, No. 1, 2001, pp. 169-170.

[13] A. Aberg, H. Rydhstroem and A. Frid, "Impaired Glucose Tolerance Associated with Adverse Pregnancy Outcome: A Population-Based Study in Southern Sweden," American Journal of Obstetrics and Gynecology, Vol. 184, No. 2, 2001, pp. 77-83. doi:10.1067/mob.2001.108085

[14] K. K. Ong, B. Diderholm, G. Salzano, D. Wingate, I. A. Hughes, J. MacDougall, et al., "Pregnancy Insulin, Glucose, and BMI Contribute to Birth Outcomes in Nondiabetic Mothers,” Diabetes Care, Vol. 31, No. 11, 2008, pp. 2193-2197. doi:10.2337/dc08-1111

[15] S. L. Kjos and T. A. Buchanan, "Gestational Diabetes Mellitus,” The New England Journal of Medicine, Vol. 341, No. 23, 1999, pp. 1749-1756. doi:10.1056/NEJM199912023412307

[16] S. L. Boulet, G. R. Alexander, H. M. Salihu and M. Pass, "Macrosomic Births in the United States: Determinants, Outcomes, and Proposed Grades of Risk," American Journal of Obstetrics \& Gynecology, Vol. 188, No. 5, 2003, pp. 1372-1378.

[17] A. Plagemann, T. Harder, R. Kohlhoff, W. Rohde and G. Dörner, "Glucose Tolerance and Insulin Secretion in Children of Mothers with Pregestational IDDM or Gestational Diabetes,” Diabetologia, Vol. 40, No. 9, 1997, pp. 10941100.

[18] S. H. Mehta, M. Kruger and R. J. Sokol, "Being Too Large for Gestational Age Precedes Childhood Obesity in African Americans," American Journal of Obstetrics \& Gynecology, Vol. 204, No. 3, 2011, pp. e261-e265. doi:10.1016/j.ajog.2010.12.009

[19] C. M. Boney, A. Verma, R. Tucker and B. R. Vohr, "Metabolic Syndrome in Childhood: Association with Birth Weight, Maternal Obesity, and Gestational Diabetes Mellitus,” Pediatrics, Vol. 115, No. 3, 2005, pp. e290-e296. doi:10.1542/peds.2004-1808

[20] M. L. Hediger, M. D. Overpeck, A. McGlynn, R. J. Kuczmarski, K. R. Maurer and W. W. Davis, "Growth and Fatness at Three to Six Years of Age of Children Born Small- or Large-for-Gestational Age,” Pediatrics, Vol. 104, No. 3, 1999, p. e33. doi:10.1542/peds.104.3.e33

[21] B. R. Vohr and S. T. McGarvey, "Growth Patterns of Largefor-Gestational-Age and Appropriate-for-Gestational-Age Infants of Gestational Diabetic Mothers and Control Mothers at Age 1 Year,” Diabetes Care, Vol. 20, No. 7, 1997, pp. 1066-1072. doi:10.2337/diacare.20.7.1066
[22] P. Catalano and H. M. Ehrenberg, "The Short- and LongTerm Implications of Maternal Obesity on the Mother and Her Offspring,” BJOG: An International Journal of Obstetrics \& Gynaecology, Vol. 113, No. 10, 2006, pp. 11261133. doi:10.1111/j.1471-0528.2006.00989.x

[23] F. A. van Assche, K. Holemans and L. Aerts, "Long-Term Consequences for Offspring of Diabetes during Pregnancy," British Medical Bulletin, Vol. 60, No. 2001, pp. 173-182. doi:10.1093/bmb/60.1.173

[24] A. Yessoufou and K. Moutairou, "Maternal Diabetes in Pregnancy: Early and Long-Term Outcomes on the Offspring and the Concept of 'Metabolic Memory'," Experimental Diabetes Research, Vol. 2011, 2011, Article ID: 218598.

[25] X. Zhang, A. Decker, R. W. Platt and M. S. Kramer, "How Big Is Too Big? The Perinatal Consequences of Fetal Macrosomia," American Journal of Obstetrics \& Gynecology, Vol. 198, No. 5, 2008, pp. 517 e511-e516. doi:10.1016/j.ajog.2007.12.005

[26] S. Rodrigues, E. J. Robinson, M. S. Kramer and K. GrayDonald, "High Rates of Infant Macrosomia: A Comparison of a Canadian Native and a Non-Native Population," Journal of Nutrition, Vol. 130, No. 4, 2000, pp. 806-812.

[27] H. Xu, F. Simonet and Z. C. Luo, “Optimal Birth Weight Percentile Cut-Offs in Defining Small- or Large-for-Gestational-Age," Acta Paediatrica, Vol. 99, No. 4, 2010, pp. 550-555. doi:10.1111/j.1651-2227.2009.01674.x

[28] G. R. Alexander, J. H. Himes, R. B. Kaufman, J. Mor and M. Kogan, "A United States National Reference for Fetal Growth,” Obstetrics \& Gynecology, Vol. 87, No. 2, 1996, pp. 163-168. doi:10.1016/0029-7844(95)00386-X

[29] R. Retnakaran, C. Ye, A. J. Hanley, P. W. Connelly, M. Sermer, B. Zinman, et al., "Effect of Maternal Weight, Adipokines, Glucose Intolerance and Lipids on Infant Birth Weight among Women without Gestational Diabetes Mellitus," Canadian Medical Association Journal, Vol. 184, No. 12, 2012, pp. 1353-1360. doi:10.1503/cmaj.111154

[30] E. Ota, M. Haruna, M. Suzuki, D. D. Anh, L. H. Tho, N. T. Tam, et al., "Maternal Body Mass Index and Gestational Weight Gain and Their Association with Perinatal Outcomes in Viet Nam,” Bull World Health Organization, Vol. 89, No. 2, 2011, pp. 127-136. doi:10.2471/BLT.10.077982

[31] K. J. Hunt, M. C. Alanis, E. R. Johnson, M. E. Mayorga and J. E. Korte, "Maternal Pre-Pregnancy Weight and Gestational Weight Gain and Their Association with Birthweight with a Focus on Racial Differences,” Maternal and Child Health Journal, 11 February 2012. doi:10.1007/s10995-012-0950-X

[32] P. Catalano, K. Farrell, A. Thomas, L. Huston-Presley, P. Mencin, S. H. de Mouzon, et al., "Perinatal Risk Factors for Childhood Obesity and Metabolic Dysregulation," The American Journal of Clinical Nutrition, Vol. 90, No. 5, 2009, pp. 1303-1313. doi:10.3945/ajcn.2008.27416

[33] D. K. Waller, G. M. Shaw, S. A. Rasmussen, C. A. Hobbs, M. A. Canfield, A. M. Siega-Riz, et al., "Prepregnancy Obesity as a Risk Factor for Structural Birth Defects," Archives of Pediatrics \& Adolescent Medicine, Vol. 161, 
No. 8, 2007, pp. 745-750.

doi:10.1001/archpedi.161.8.745

[34] J. L. Mills, J. Troendle, M. R. Conley, T. Carter and C. M. Druschel, "Maternal Obesity and Congenital Heart Defects: A Population-Based Study,” The American Journal of Clinical Nutrition, Vol. 91, No. 6, 2010, pp. 1543-1549. doi:10.3945/ajcn.2009.28865

[35] S. M. Gilboa, A. Correa, L. D. Botto, S. A. Rasmussen, D. K. Waller, C. A. Hobbs, et al., "Association between Prepregnancy Body Mass Index and Congenital Heart Defects," American Journal of Obstetrics \& Gynecology, Vol. 202, No. 1, 2010, pp. 51 e1-51 e10. doi:10.1097/01.aoa.0000389577.48331.d9

[36] S. A. Rasmussen, S. Y. Chu, S. Y. Kim, C. H. Schmid and J. Lau, "Maternal Obesity and Risk of Neural Tube Defects: A Metaanalysis,” American Journal of Obstetrics \& Gynecology, Vol. 198, No. 6, 2008, pp. 611-619. doi:10.1016/j.ajog.2008.04.021

[37] J. G. Ray, P. R. Wyatt, M. J. Vermeulen, C. Meier and D. E. Cole, "Greater Maternal Weight and the Ongoing Risk of Neural Tube Defects after Folic Acid Flour Fortification,” Obstetrics \& Gynecology, Vol. 105, No. 2, 2005, pp. 261-265. doi:10.1097/01.AOG.0000151988.84346.3e

[38] S. Y. Chu, W. M. Callaghan, S. Y. Kim, C. H. Schmid, J. Lau, L. J. England, et al., "Maternal Obesity and Risk of Gestational Diabetes Mellitus,” Diabetes Care, Vol. 30, No. 8, 2007, pp. 2070-2076. doi:10.2337/dc06-2559a

[39] T. Y. Leung, T. N. Leung, D. S. Sahota, O. K. Chan, L. W. Chan, T. Y. Fung, et al., "Trends in Maternal Obesity and Associated Risks of Adverse Pregnancy Outcomes in a Population of Chinese Women,” BJOG: An International Journal of Obstetrics \& Gynaecology, Vol. 115, No. 12, 2008, pp. 1529-1537. doi:10.1111/j.1471-0528.2008.01931.x

[40] M. Tabatabaei, “Gestational Weight Gain, Prepregnancy Body Mass Index Related to Pregnancy Outcomes in KAZERUN, FARS, IRAN," Journal of Prenatal Medicine, Vol. 5, No. 2, 2011, pp. 35-40.

[41] P. Catalano, H. D. McIntyre, J. K Cruickshank, D. R. McCance, A. R. Dyer, B. E. Metzger, et al., "The Hyperglycemia and Adverse Pregnancy Outcome Study: Associations of GDM and Obesity with Pregnancy Outcomes,” Diabetes Care, Vol. 35, No. 4, 2012, pp. 780-786. doi:10.2337/dc11-1790

[42] T. A. Hillier, K. L. Pedula, K. K. Vesco, M. M. Schmidt, J. A. Mullen, E. S. LeBlanc, et al., "Excess Gestational Weight Gain: Modifying Fetal Macrosomia Risk Associated with Maternal Glucose," Obstetrics \& Gynecology, Vol. 112, No. 5, 2008, pp. 1007-1014. doi:10.1097/AOG.0b013e31818a9779

[43] P. Catalano, A. Thomas, L. Huston-Presley and S. B. Amini, "Increased Fetal Adiposity: A Very Sensitive Marker of Abnormal in Utero Development," American Journal of Obstetrics \& Gynecology, Vol. 189, No. 6, 2003, pp. 16981704. doi:10.1016/S0002-9378(03)00828-7

[44] S. Hester, D. Hustead, A. Mackey, A. Singhal and B. Marriage, "Is the Macronutrient Intake of Formula-Fed Infants Greater Than Breast-Fed Infants in Early Infancy?” Journal of Nutrition and Metabolism, Vol. 2012, 2012,
Article ID: 891201. doi:10.1155/2012/891201

[45] B. Durmus, D. O. Mook-Kanamori, S. Holzhauer, A. Hofman, E. M. van der Beek, G. Boehm, et al., "Growth in Foetal Life and Infancy Is Associated with Abdominal Adiposity at the Age of 2 Years: The Generation R Study," Clinical Endocrinology, Vol. 72, No. 5, 2010, pp. 633-640. doi:10.1111/j.1365-2265.2009.03708.x

[46] S. Holzhauer, A. C. Hokken Koelega, M. Ridder, A. Hofman, H. A. Moll, E. A. Steegers, et al., "Effect of Birth Weight and Postnatal Weight Gain on Body Composition in Early Infancy: The Generation R Study,” Early Human Development, Vol. 85, No. 5, 2009, pp. 285-290. doi:10.1016/j.earlhumdev.2008.11.002

[47] A. Singhal, M. Fewtrell, T. J. Cole and A. Lucas, "Low Nutrient Intake and Early Growth for Later Insulin Resistance in Adolescents Born Preterm,” The Lancet, Vol. 361, No. 9363, 2003, pp. 1089-1097. doi:10.1016/S0140-6736(03)12895-4

[48] A. Singhal, T. J. Cole, M. Fewtrell, J. Deanfield and A. Lucas, "Is Slower Early Growth Beneficial for LongTerm Cardiovascular Health?” Circulation, Vol. 109, No. 9, 2004, pp. 1108-1113. doi:10.1161/01.CIR.0000118500.23649.DF

[49] N. Stettler, V. A. Stallings, A. B. Troxel, J. Zhao, R. Schinnar, S. E. Nelson, E. E. Ziegler and B. L. Strom, "Weight Gain in the First Week of Life and Overweight in Adulthood: A Cohort Study of European American Subjects Fed Infant Formula," Circulation, Vol. 111, No. 15, 2005, pp. 1897-1903. doi:10.1161/01.CIR.0000161797.67671.A7

[50] K. Baptiste-Roberts, W. K. Nicholson, N. Y. Wang and F. L. Brancati, "Gestational Diabetes and Subsequent Growth Patterns of Offspring: The National Collaborative Perinatal Project," Maternal and Child Health Journal, Vol. 16, No. 1, 2012, pp. 125-132. doi:10.1007/s10995-011-0756-2

[51] L. Touger, H. C. Looker, J. Krakoff, R. S. Lindsay, V. Cook and W. C. Knowler, "Early Growth in Offspring of Diabetic Mothers," Diabetes Care, Vol. 28, No. 3, 2005, pp. 585-589. doi:10.2337/diacare.28.3.585

[52] A. Fraser, K. Tilling, C. Macdonald-Wallis, N. Sattar, M. J. Brion, L. Benfield, et al., "Association of Maternal Weight Gain in Pregnancy with Offspring Obesity and Metabolic and Vascular Traits in Childhood," Circulation, Vol. 121, No. 23, 2010, pp. 2557-2564. doi:10.1161/CIRCULATIONAHA.109.906081

[53] J. K. Hamilton, J. Yin, A. J. Hanley, B. Zinman and R. Retnakaran, "Maternal Insulin Sensitivity during Pregnancy Predicts Infant Weight Gain and Adiposity at 1 Year of Age," Obesity, Vol. 18, No. 2, 2010, pp. 340-346. doi:10.1038/oby.2009.231

[54] M. F. Sewell, L. Huston-Presley, D. M. Super and P. Catalano, "Increased Neonatal Fat Mass, Not Lean Body Mass, Is Associated with Maternal Obesity," American Journal of Obstetrics \& Gynecology, Vol. 195, No. 4, 2006, pp. 11001103. doi:10.1016/j.ajog.2006.06.014

[55] U. M. Schaefer-Graf, K. Graf, I. Kulbacka, S. L. Kjos, J. Dudenhausen, K. Vetter and E. Herrera, "Maternal Lipids as Strong Determinants of Fetal Environment and Growth 
in Pregnancies with Gestational Diabetes Mellitus," Diabetes Care, Vol. 31, No. 9, 2008, pp. 1858-1863. doi:10.2337/dc08-0039

[56] P. Catalano, J. Shao, L. Preston, L. Qiao and J. E. Friedman, "Downregulated IRS-1 and PPARgamma in Obese Women with Gestational Diabetes: Relationship to FFA during Pregnancy," American Journal of Physiology. Endocrinology and Metabolism, Vol. 282, No. 3, 2001, pp. E522E533.

[57] A. Plagemann, "A Matter of Insulin: Developmental Programming of Body Weight Regulation," Journal of Maternal-Fetal and Neonatal Medicine, Vol. 21, No. 3, 2008, pp. 143-148. doi:10.1080/14767050801929869

[58] A. Plagemann, "Perinatal Programming and Functional Teratogenesis: Impact on Body Weight Regulation and Obesity,” Physiology \& Behavior, Vol. 86, No. 5, 2005, pp. 661-668. doi:10.1016/j.physbeh.2005.08.065

[59] G. Dörner and A. Plagemann, "Perinatal Hyperinsulinism as Possible Predisposing Factor for Diabetes Mellitus, Obesity and Enhanced Cardiovascular Risk in Later Life," Hormone and Metabolic Research, Vol. 26, No. 5, 1994, pp. 213-221. doi:10.1055/s-2007-1001668

[60] S. P. Kalra and P. S. Kalra, "Nutritional Infertility: The Role of the Interconnected Hypothalamic Neuropeptide Y-Galanin-Opioid Network," Front Neuroendocrinol, Vol. 17, No. 4, 1996, pp. 371-401. doi:10.1006/frne.1996.0010

[61] K. L. Howdeshell, "A Model of the Development of the Brain as a Construct of the Thyroid System," Endocrine Disruptors, Vol. 110, No. 3, 2002, pp. 337-348. doi:10.1289/ehp.02110s3337

[62] P. Catalano, S. Haugel-de Mouzon and J. King, “Gestational Diabetes and Insulin Resistance: Role in Short- and LongTerm Implications for Mother and Fetus," The Journal of Nutrition, Vol. 133, No. 5, 2003, pp. 1674s-1683s.

[63] B. E. Metzger, L. P. Lowe, A. R. Dyer, J. K. Cruickshank, C. Deerochanawong, H. L. Halliday, et al., "Hyperglycemia and Adverse Pregnancy Outcome Study: Neonatal Glycemia,” Pediatrics, Vol. 126, No. 6, 2010, pp. 1545-1552. doi:10.1542/peds.2009-2257

[64] P. K. Hillier, M. M. Schmidt, J. A. Mullen, M. A. Charles and D. J. Pettitt, "Childhood Obesity and Metabolic Imprinting: The Ongoing Effects of Maternal Hyperglycemia,” Diabetes Care, Vol. 30, No. 9, 2007, pp. 2287-2292. doi:10.2337/dc06-2361

[65] P. Catalano, "Obesity and Pregnancy-The Propagation of a Viscous Cycle?” Journal of Clinical Endocrinology and Metabolism, Vol. 88, No. 8, 2003, pp. 3505-3506. doi:10.1210/jc.2003-031046

[66] E. Oken, S. L. Rifas-Shiman, A. E. Field, A. L. Frazier and M. W. Gillman, "Maternal Gestational Weight Gain and Offspring Weight in Adolescence,” Obstetrics \& Gynecology, Vol. 112, No. 5, 2008, pp. 999-1006. doi:10.1097/AOG.0b013e31818a5d50

[67] IOM (Institute of Medicine) and NRC (National Research Council), "Weight Gain during Pregnancy: Reexamining the Guidelines,” The National Academies Press, Washington, 2009.

[68] L. M. Bodnar, A. M. Siega-Riz, H. N. Simhan, K. P. Himes and B. Abrams, "Severe Obesity, Gestational Weight
Gain, and Adverse Birth Outcomes," The American Journal of Clinical Nutrition, Vol. 91, No. 6, 2010, pp. 1642-1648. doi:10.3945/ajcn.2009.29008

[69] K. M. Rasmussen, P. M. Catalano and A. L. Yaktine, "New Guidelines for Weight Gain during Pregnancy: What Obstetrician/Gynecologists Should Know," Current Opinion in Obstetrics and Gynecology, Vol. 21, No. 6, 2009, pp. 521-526. doi:10.1097/GCO.0b013e328332d24e

[70] J. M. Crane, J. White, P. Murphy, L. Burrage and D. Hutchens, "The Effect of Gestational Weight Gain by Body Mass Index on Maternal and Neonatal Outcomes," Journal of Obstetrics and Gynaecology Canada, Vol. 31, No. 1, 2009, pp. 28-35.

[71] L. A. Schieve, M. E. Cogswell and K. S. Scanlon, “Trends in Pregnancy Weight Gain within and Outside Ranges Recommended by the Institute of Medicine in a WIC Population," Maternal and Child Health Journal, Vol. 2, No. 2, 1998, pp. 111-116. doi:10.1023/A:1022992823185

[72] K. M. Flegal, M. D. Carroll, C. L. Ogden and L. R. Curtin, "Prevalence and Trends in Obesity among US Adults, 1999-2008," Journal of the American Medical Association, Vol. 303, No. 3, 2010, pp. 235-241. doi:10.1001/jama.2009.2014

[73] E. Villamor and S. Cnattingius, "Interpregnancy Weight Change and Risk of Adverse Pregnancy Outcomes: A Population-Based Study,” Lancet, Vol. 368, No. 9542, 2006, pp. 1164-1170. doi:10.1016/S0140-6736(06)69473-7

[74] O. E. Herring, S. L. Rifas-Shiman, J. W. Rich-Edwards, A. M. Stuebe, K. P. Kleinman and M. W. Gillman, "Weight Gain in Pregnancy and Risk of Maternal Hyperglycemia," Vol. 201, No. 1, 2009, pp. e61-e67. doi:10.1016/j.ajog.2009.01.039

[75] A. Tovar, A. Must, O. I. Bermudez, R. R. Hyatt and L. Chasan-Taber, "The Impact of Gestational Weight Gain and Diet on Abnormal Glucose Tolerance during Pregnancy in Hispanic Women," Maternal and Child Health Journal, Vol. 13, No. 4, 2009, pp. 520-530.

[76] Y. W. Cheng, J. H. Chung, I. Kurbisch-Block, M. Inturrisi, S. Shafer and A. B. Caughey, "Gestational Weight Gain and Gestational Diabetes Mellitus: Perinatal Outcomes," Obstetrics \& Gynecology, Vol. 112, No. 5, 2008, pp. 1015-1022. doi:10.1097/AOG.0b013e31818b5dd9

[77] J. Laitinen, A. Jaaskelainen, A. L. Hartikainen, U. Sovio, M. Vaarasmaki, A. Pouta, M. Kaakinen and M. R. Jarvelin, "Maternal Weight Gain during the First Half of Pregnancy and Offspring Obesity at 16 Years: A Prospective Cohort Study," BJOG: An International Journal of Obstetrics \& Gynaecology, Vol. 119, No. 6, 2012, pp. 716-723. doi:10.1111/j.1471-0528.2012.03319.x

[78] W. H. Dietz, "Periods of Risk in Childhood for the Development of Adult Obesity-What Do We Need to Learn?” Journal of Nutrition, Vol. 127, No. 9, 1997, pp. 1884S1886S.

[79] A. S. Morisset, A. St-Yves, J. Veillette, S. J. Weisnagel, A. Tchernof and J. Robitaille, "Prevention of Gestational Diabetes Mellitus: A Review of Studies on Weight Management," Diabetes/Metabolism Research and Reviews, Vol. 26, No. 1, 2010, pp. 17-25. doi:10.1002/dmrr.1053

[80] E. Oteng-Ntim, R. Varma, H. Croker, L. Poston and P. Doy- 
le, "Lifestyle Interventions for Overweight and Obese Pregnant Women to Improve Pregnancy Outcome: Systematic Review and Meta-Analysis,” BMC Medicine, Vol. 10, No. 47, 2012, p. 47. doi:10.1186/1741-7015-10-47

[81] I. Tanentsapf, B. L. Heitmann and A. R. Adegboye, "Systematic Review of Clinical Trials on Dietary Interventions to Prevent Excessive Weight Gain during Pregnancy among Normal Weight, Overweight and Obese Women," BMC Pregnancy Childbirth, Vol. 11, No. 81, 2011, p. 81. doi:10.1186/1471-2393-11-81

[82] S. Thangaratinam, E. Rogozinska, K. Jolly, S. Glinkowski, T. Roseboom, J. W. Tomlinson, et al., "Effects of Interventions in Pregnancy on Maternal Weight and Obstetric Outcomes: Meta-Analysis of Randomised Evidence," $B M J$, Vol. 344, 2012, p. e2088. doi:10.1136/bmj.e2088

[83] S. Chomtho, J. C. Wells, P. S. Davies, A. Lucas and M. S. Fewtrell, "Early Growth and Body Composition in Infancy," Advances in Experimental Medicine and Biology, Vol. 646, 2009, pp. 165-168.

[84] R. E. Harder, T, K. Schellong, J. W. Dudenhausen and A. Plagemann, "Birth Weight and Subsequent Risk of Type 2 Diabetes: A Meta-Analysis,” American Journal of Epidemiology, Vol. 165, No. 8, 2007, pp. 849-857. doi:10.1093/aje/kwk071

[85] K. Bowers, G. Liu, P. Wang, T. Ye, Z. Tian, E. Liu, et al., "Birth Weight, Postnatal Weight Change, and Risk for
High Blood Pressure among Chinese Children,” Pediatrics, Vol. 127, No. 5, 2011, pp. e1272-e1279. doi:10.1542/peds.2010-2213

[86] J. Baird, D. Fisher, P. Lucas, J. Kleijnen, H. Roberts and C. Law, "Being Big or Growing Fast: Systematic Review of Size and Growth in Infancy and Later Obesity,” BMJ, Vol. 331, No. 7522, 2005, p. 929. doi:10.1136/bmj.38586.411273.E0

[87] P. O. Monteiro and C. G. Victora, "Rapid Growth in Infancy and Childhood and Obesity in Later Life-A Systematic Review,” Obesity Reviews, Vol. 6, No. 2, 2005, pp. 143-154. doi:10.1111/j.1467-789X.2005.00183.x

[88] K. K. Ong, "Size at Birth and Early Childhood Growth in Relation to Maternal Smoking, Parity and Infant BreastFeeding: Longitudinal Birth Cohort Study and Analysis," Pediatric Research, Vol. 52, No. 6, 2002, pp. 863-867. doi:10.1203/00006450-200212000-00009

[89] A. Singhal and A. Lucas, "Early Origins of Cardiovascular Disease: Is There a Unifying Hypothesis?” The Lancet, Vol. 363, No. 9421, 2004, pp. 1642-1645. doi:10.1016/S0140-6736(04)16210-7

[90] C. E. Elks, R. J. Loos, S. J. Sharp, C. Langenberg, S. M. Ring, N. J. Timpson, et al., "Genetic Markers of Adult Obesity Risk Are Associated with Greater Early Infancy Weight Gain and Growth,” PLOS Medicine, Vol. 7, No. 5, 2010, Article ID: e1000284. doi:10.1371/journal.pmed.1000284 